Levels and equivalence in credit and qualifications frameworks: Contrasting the prescribed and enacted curriculum in school and college

Kate Miller, Richard Edwards and Mark Priestley

The Stirling Institute of Education

University of Stirling

Stirling FK9 4LA 


\begin{abstract}
Drawing on data from an empirical study of three matched subjects in upper secondary school and further education college in Scotland, this article explores some of the factors that result in differences emerging from the translation of the prescribed curriculum into the enacted curriculum. We argue that these differences raise important questions about equivalences which are being promoted through the development of credit and qualifications frameworks. The article suggests that the standardisation associated with the development of a rational credit and qualifications framework and an outcomes-based prescribed curriculum cannot be achieved precisely because of the multiplicity that emerges from the practices of translation.
\end{abstract}

Keywords: prescribed curriculum; enacted curriculum; credit frameworks; learning outcomes; translation 


\section{Levels and equivalence in credit and qualifications frameworks: Contrasting the prescribed and enacted curriculum in school and college}

\section{Introduction}

Over the years, there have been significant changes in the boundaries between secondary schooling and further education in the UK. As a result, there are increasing attempts to develop more vocational routes in schools and also more 14-16 year olds are attending courses at colleges. Alongside these are attempts to create greater "parity of esteem' between different pathways in the curriculum through the establishment of credit and qualifications frameworks. Within these frameworks, different subjects and qualifications are ascribed a level, which, in principle, allows for equivalences across different forms of learning to be evaluated. In Scotland, this work is being undertaken under the auspices of the Scottish Credit and Qualifications Framework (SCQF).

Credit and qualifications frameworks arise from and produce a rational view of the prescribed curriculum, as once a level is ascribed and accepted, it becomes straightforward to map recruitment and progression routes for students to different goals. There is a logical flexibility in such systems. However, questions still remain over the nature and extent of similarities and differences in the enacted curriculum in different sites and the empirical flexibility they may or may not enable. Here we take the prescribed curriculum (Bloomer 1997) as that inscribed in unit descriptors and outcome statements and the enacted curriculum to refer to the choreographing of people, spaces and artefacts in the enactment of practices - cognitive, practical, communicative - designated as learning. At one level, the specification of learning outcomes at particular levels within a common framework points to a rational 
curriculum within which attainment and progression are, in principle, transparent. Learning at the same level is assumed to be equivalent. However, while this may be the case in relation to the prescribed curriculum, what interests us are the differences and similarities that emerge through the translation and contextualisation of the prescribed curriculum into different sites, into what is enacted as learning and teaching.

This article presents and discusses some findings from an ESRC (Economic and Social Research Council) funded project that has sought to explore the curriculummaking practices in upper secondary school and college in the context of Scotland. By examining curriculum making in three matched subjects and units within the two sites, we have sought to identify similarities and differences between them, and also the factors which are at play in the translations of the rational prescribed curriculum into enacted practice.

The article is in three sections. First we outline the background to the project, the questions addressed and the methods adopted. Second, we draw upon data from the three curriculum areas we have researched - Hospitality, Life Sciences and Technical Studies - to outline some of the factors that influence the translations from the prescribed to enacted curriculum. Finally, we draw out some inferences for curriculum policy and pedagogy from our analysis. While the setting of this study is Scotland, the issues raised have wider ramifications, given the interest in different routes through education and the attempts to develop both national and cross national credit frameworks. 


\section{Background}

Historically, in Scotland, schools focused on an academic curriculum, while colleges provided a more occupation-related curriculum (Bryce and Humes 1999, Leech 1999). This has changed, as some schools have sought to provide more occupationally-oriented opportunities for students for whom the academic curriculum may be less appropriate, while colleges have developed their provision of the higher level occupation-related curriculum and also developed academic opportunities for students (Thomson 2003, Canning 2007). The result is that currently parts of the curriculum are common to both schools and colleges, both organisations providing learning opportunities for the 14-18 age range, and there are increasing numbers of students attending both school and college at the same time. These changes impact upon curriculum coherence, transition and progression for students within the curriculum and between institutional contexts.

In Scotland, two significant developments are the Scottish Qualifications Authority (SQA) and the Scottish Credit and Qualifications Framework (SCQF). The SQA acts as a single awarding body for qualifications other than university awards. It therefore provides a single framework for both schools and colleges. The SCQF seeks to provide equivalence between different forms of learning and awards, to provide the possibility for credit accumulation and transfer between institutions and qualifications. The SQA sets its awards within the SCQF structure of levels and credits. To a greater or lesser extent, colleges and schools both offer courses at levels 2-7, although most colleges also offer higher level courses. 
It is the outcomes-based SQA unit descriptors which schools and colleges mainly utilise when developing a curriculum in particular subjects. These provide the basis for the prescribed curriculum. In theory, there are many curriculum routes to achieve the outcomes; this provides the possibility for creative approaches to pedagogy on the part of institutions, departments and teachers/lecturers (Osborn et al. 1997, Higham 2003). It is such possibilities that are often represented in the described curriculum (Bloomer 1997), those narratives of practice, often aspirational, provided by teachers and lecturers.

However, research evidence suggests that there is less diversity in the described and enacted curriculum than envisioned or desired (e.g. Cohen 1988, Smyth et al. 1998). Indeed many unit descriptors would seem to seek greater standardisation, as they do not only specify outcomes, but also make broad statements about expectations in relation to teaching, learning and assessment practices to achieve those goals, thereby seeming to limit the possibilities for diversity. Many of the reforms in curriculum since the 1980s have been characterised as a top-down, centre-periphery model of dissemination, described by Goodson (2003, xiii) as 'brutal restructuring' delivered in 'ignorance or defiance of teachers' beliefs and missions'. At one level, this apparent standardisation might be said to be a good thing as it provides the basis for greater trust in the equivalence of learning within the qualifications frameworks. However, it might also be said to stifle diversity and creativity in the enacted curriculum.

Analysis of the introduction of National Qualification Frameworks (NQFs) in other countries can help throw light on some of the epistemological issues related to the implementation of NQFs. Young (2007) states that (NQFs) are often seen as laying 
down a set of outcomes which can drive the reform of education and training and regulate the form that qualifications take. He takes issue with this and argues that such an approach to NQFs involves an inappropriate role for outcomes or national standards that they can not fulfil. He distinguishes between countries with relatively developed institutional provision and developing countries with less developed institutional provision. He argues that in the former such an approach can undermine many of the strengths of traditional systems and in the latter it can be a distraction from developing institutional capability and enhancement of the curriculum. Allais (2007), in her analysis of the South African model, identifies it as being strongly outcomes-led where the key to the model is the principle that qualifications and unit standards must be composed of learning outcomes defined by stakeholder-based structures separately from any particular institution or learning programme.

Outcomes-based qualifications were seen to be a solution to the educational and economic problems of apartheid. It was thought that organising all qualifications and parts of qualifications on a hierarchy of levels would force society to value types of learning programmes which had historically been of low status and society would change its views about vocational qualifications which were placed on the same level of the NQF as academic qualifications. Allais describes the South African model as a failure, due to it's over specification derived from top down policy initiatives which do not take into account the complexity of knowledge acquisition.

Raffe (2007) points out that epistemological barriers to the development of unified NQFs arise because of the difficulty of fitting different types of learning - such as academic and vocational - into a single framework. He argues that in Scotland epistemological issues rarely presented overt barriers in the same way as they have in 
other countries such as South Africa and New Zealand. This is partly explained in terms of the looseness of the framework, which has been able to bridge different epistemologies and partly by the voluntary nature of the implementation. Raffe identifies the strongest barriers to a unified qualification framework in Scotland to have been institutional. He argues that the Scottish experience has shown how different sectors have different institutional logics which resist the attempt to superimpose a uniform intrinsic logic.

Further, a great deal of research points to a tendency for continuity rather than change in what goes on in schools and colleges in response to centrally mandated reform initiatives (e.g. Cuban 1988, Sarason 1990, Helsby 1999, Lang et al. 1999, Spillane 1999, Goodson 2004). For example, in relation to the school curriculum, Eisner $(1992,610)$ stated that 'it is much easier to change educational policy than to change the ways in which schools function'. Tyack and Cuban $(1995,88)$ talked of the difficulties in changing the grammar of schooling, those 'institutional habits and widespread cultural beliefs about what constitutes a "real school"'. Cuban (1984) identified a number of stability factors in schools that militate against change in practice, for example: schools prize obedience over independent thinking; the pragmatics of organisational structures; the existing culture of teaching; those who avoid risk are rewarded; and the socialisation of teachers through their own schooling.

Such stability factors and the persistence of established practices therefore contribute to the gaps between the prescribed, described and the enacted curricula, despite the supposed standardisation imposed through the first of these. The latter two aspects of 
the curriculum might show some modifications, but change has been assimilated into the existing subject and organisational culture.

The research thus suggests that attempts to provide a rational prescribed curriculum with equivalences across sites is not being achieved in the enacted curriculum, which raises questions about the presumed equivalence of learning and the opportunities for progression for students. Existing research also identifies a range of factors which influence and militate against diversity in curriculum-making. This is significant insofar as curriculum reforms can be absorbed into existing organisational and professional cultures rather than being a vehicle to transform them (Cuban 1998, Elmore 2004, Mueller and Hovde 2008). Thus, while in the prescribed curriculum there is a notional equivalence in terms of outcomes at a certain level of performance, in the enacted curriculum there can be a great deal of difference, which itself then raises questions about the formal equivalences established.

The factors affecting curriculum making in these settings can be identified at various levels, using a simple heuristic:

- contextual factors e.g. national policy, funding arrangements;

- organisational factors e.g. nature and size of institution and subject department, styles of management, level and type of resources, locus of decision-making, internal or external assessments;

- curriculum factors e.g. the ways in which the curriculum is prescribed, nature of the curriculum i.e. academic or vocational;

- micro-political factors e.g. collegial, hierarchical or individualistic, expectations of students and parents; 
- and individual factors e.g. professional formation and dispositions of lecturers and teachers, student backgrounds and prior experiences.

Thus, for instance, the availability of published textbooks and other resources, and teachers' existing frames of reference act to enable and constrain curriculum-making in certain ways. Bates (1989) stressed the importance of teachers' material, especially career interests, in determining how new initiatives are mediated. Doyle and Ponder (1977) suggested that teachers have a 'practicality ethic' which means new practices emerge when they are congruent with existing values, are instrumental and the benefits are perceived to outweigh the costs. Daniels (2001) refers to 'stuck' and 'moving' schools to contrast those in which teachers are less willing to take risks and those where this is not the case. It is argued that one factor affecting this is a contrast between a hierarchical and collaborative culture. While most of the existing studies focus on curriculum making in schools, these factors could also be relevant in curriculum-making in the college context also (James and Biesta 2007).

The data, upon which the remainder of this article draws, were generated in two associated sites, a secondary school and a college of further education in a medium sized town in Scotland. We have explored these issues in the context of the following three curriculum areas, drawing data from various SQA courses at Intermediate 2 (SCQF level 5) and Higher (SCQF level 6) levels.

- Hospitality: Practical cookery for the Hospitality Industry - Intermediate 2, Pauline (Woodland Academy) and Professional Cookery -Intermediate 2, Malcolm (Riverside College)

- Life Sciences: Biology Intermediate 2, Donald and Debbie (Woodland Academy) and Biology Intermediate 2, Isabelle (Riverside College). 
- Higher Technical Studies: Gerald (Woodland Academy) and Higher Mechatronics, Duncan (Riverside College).

These have been taken as telling cases. Within each site, units of the same SCQF level were matched and studied. Units within the individual curriculum areas had similar or identical learning outcomes specified in the prescribed curriculum. The students on each unit were all 16-18. This was to enable as close a comparison across organisational sites as possible. Data were derived from existing SQA unit descriptors, and cycles of classroom observations and interviews with staff and students on the selected units over the course of one term in the autumn of 2007. For each curriculum area, the teacher in the school and lecturer in the college was interviewed initially to obtain background information about their work experience and preferred approaches to teaching. These interviews were followed by two classroom observations then further interviews to explore the practices of those classes. A further two observations and a final interview with each teacher were then carried out. Observations were carried out in light of the teachers' own descriptions of their approach to the curriculum. The observations were guided by observation schedules derived from the teacher's descriptions of their approach to teaching and from the texts associated with the prescribed curriculum relating to individual classes. Observation notes were then written up and used to guide the subsequent interviews and focus groups. Interviews with the teachers then explored any critical incidences or apparent inconsistencies between the prescribed, described and enacted curriculum. Focus groups took place with a sample of students after each classroom observation to explore the students' perceptions of those classes and their own contributions to the enacted curriculum. Transcripts and observation notes were then subject to descriptive interpretation to produce detailed case studies and thematic analysis for cross site 
comparison. Pseudonyms have been used for the school and college, and for individuals to protect the anonymity of respondents.

\section{Cultures of curriculum making}

Thematic analysis of the data indicates that two of the factors in the heuristic outlined above exhibit the greatest importance in helping to explain the processes of curriculum making for teachers/lecturers and students in those sites: these are individual and organisational factors. This is not to deny other factors that influence translations from the prescribed to the enacted curriculum. However, within the context of this article we want to focus on those that have emerged as most important for the participants. The following sections therefore provide analysis of each case study in respect of the individual and organisational factors influencing curriculum making.

\section{Hospitality}

\section{Individual factors}

Pauline went from school to university then back into school as a teacher. She had been teaching at the school for eight years, and this was her only school. Her mother was a head teacher of a primary school. 'I vowed I would never be a teacher... the thought of secondary scared the living daylights out of me' (Pauline). However, after two weeks on a school placement while doing her undergraduate degree, she 'just got such a buzz out of it, such buzz'. Her lack of commercial experience and external connections was reflected in a lack of awareness of how things are developed at SQA. Pauline tended to follow the sessions as laid down in her materials, although with 
occasional deviations. She could be said to have a strong subject focus in her teaching, with the purpose of getting students through their assessment. Any wider curriculum purpose beyond subject coverage in the direction of the hospitality industry appeared to be limited, despite the taught unit being focused on skills for that industry.

Pauline followed the learning outcomes as prescribed - they were displayed on a computer screen at the front of each class observed - although with creative flourishes. She was however critical of the types of meals that were specified as necessary for assessment. She felt the assessed meal reflected individual dishes put together for the purpose of demonstrating assessment criteria rather than combinations of dishes that worked well together. She brought an enthusiasm about food and a professionalism based on taste and design to her teaching. She was very loyal to her colleagues and proud of their department and what they could offer to the students. She was also very concerned about how the decisions of the senior management team around funding and availability of a range of different units and qualifications would impact on some of the students' progression routes into hospitality and care-related occupations.

By contrast, Malcolm's experience as a chef and his contacts in the hospitality industry meant that he had a very clear sense that he was preparing students for the occupation. This curriculum purpose resulted in Malcolm introducing elements into his teaching that enhanced the prescribed curriculum specifically around preparing students for the industry. Malcolm had a clear view of the different aspects to hospitality that need to be learned - 'the food-side... the customer-side... the 
hygiene-side... the safety-side'. The practical focus to the curriculum was valued by the students. Malcolm tried to develop their understanding of the theory aspects of the course by drawing upon the practical, but this was not unproblematic. It was a 'curriculum for the industry' (Malcolm). He saw theory and practice as going handin-hand, although there seemed to be some tension between this and the differentiation between the kitchen (practical) and classroom (theoretical) sessions.

Malcolm recognised the importance of contacts in the industry for students to obtain work and encouraged this through inviting external contributions to the course, taking students on external visits to hospitality venues and encouraging students to have parttime work in the area. He was clear about the orientation as an occupationally oriented course aiming towards a 'professional cooking exam'. Interestingly, given the position of the hospitality teaching in the Home Economics department of the school, Malcolm explicitly differentiated 'professional hospitality' from 'home economics'. Malcolm identified the staff in schools as not having the relevant experience to provide the professional focus. He contrasted himself as 'tutor' with a 'teacher'.

Malcolm's personal commitment to hospitality was evidenced by the way he promoted it to potential students - 'I really gonna sell hospitality', 'I have a passion about it'. He talked in enthusiastic terms of teaching - 'I still enjoy it. I love it'. He bought books about cookery and brought them into the college for students to use. He also recognised the intensity for students - 'they're having to learn new things every second they come in'. 
Malcolm also saw himself as treating the students as adults, giving them more autonomy. In the class he liked to negotiate rules and expectations with students. However, the views from the students were more mixed. Most identified their engagement with Malcolm as different from school, but not always as clearly as Malcolm himself saw it. This points to the importance of the students as actors in the curriculum-making process.

The college students often had prior experiences of working in hospitality and a clear desire that this was their career direction. The role of other members of their families in working in hospitality also seemed significant in terms of the reproduction of occupational aspirations. A number of students also aspired to join the armed forces and saw hospitality as an occupation to follow therein. This raised interesting potential tensions between Malcolm's understanding of hospitality in relation to commercial restaurants and the students' aspiration to learn catering for the armed services.

Some of the college students expressed themselves as having bad school experiences. This reflects a tradition in colleges of offering educational opportunities to students who do not do well in school. Contrasting their experience of college with school was common. At school 'just loads of information chucked at you, and you're meant to learn it' $(\mathrm{N})$. $\mathrm{N}$ saw the teaching in college as being treated more like an adult - 'in a way its up to you whether you want to learn or not, rather than being told you have to learn it'. The culture of the class was less focused on explicit discipline than school, although the practical discipline of the kitchen was also apparent. Some students liked 
help from staff but not in the way it was provided in school. Other students liked to try things out for themselves.

By contrast, the school students were very different in terms of background and aspirations. Like the students in college, some students had connections into the occupation. However, all these students aspired to go to university rather than into the workplace. For some students in the group, studying cookery was seen as relatively easy by contrast with other more academic subjects; 'it's a bit different... it breaks up the day a bit, than sitting in the classroom'.

The background and aspirations of the students from the school and the college appear to match their teachers/lecturers' backgrounds in at least some respects. Malcolm had left school early having had a rather unsatisfactory experience at school. He went into the industry and learnt the trade from his professional practice and training. Pauline stayed on at school and then went on to university to do an occupationally orientated degree before specialising in teaching. Malcolm's focus in his teaching is on preparing the students for the industry and sharing his passion for food and his broader ethos on life. Pauline's focus is on the food and the artistic aspects of food preparation and appreciation. The students studying hospitality at school have not been rejected by the school, nor have they rejected it. The students at the college have all rejected or been rejected by the schools they attended and are looking for something different. Many are still exploring their interests. The prescribed curriculum is really not very different on paper, but the college environment in terms of spaces, artefacts, rules and interactions are significantly different from their perspective. 
The occupational orientation of the college enacted curriculum can be contrasted with that in the school, reflecting wider institutional culture as well as the differing backgrounds and aspirations of both staff and students. However, in one respect, there is also a great similarity for students. All students positively contrasted learning in the kitchen environment with more conventional classrooms. So, while their study of Hospitality did not always arise from direct interest in the subject, nor in moving into the occupation, the students at school, like those at college, valued its more practical nature. In other words, it was the participative form of learning that engaged them more than the acquiring of knowledge.

\section{Organisational factors}

Organisational factors that influenced curriculum-making in these cases included the nature and size of the institution and subject departments, styles of management, level and type of resources, the organisation of space and time, and the locus of decisionmaking. The Hospitality department in the college had a large staff base with a variety of expertise across the industry to draw upon. They also worked closely with staff in other subjects - e.g. Enterprise and Social Studies - to pool resources and provide cross-curricular projects. They also had themed nights in the restaurant where the students invited the Drama and Language students to help with entertainment.

The Hospitality department in the school mainly consisted of part-time female staff with little or no direct experience of the industry. They did have other experience and expertise to draw on, but this contributed to a distinctly female and more domestic feel to the way the curriculum was enacted. There was a high degree of loyalty and 
cooperative working between the members of the department, but less cross-curricular working.

In the school, the timetabling had an impact on size of class, which impacted upon the type and level of interactions between the teacher and students. The class size for the researched unit was originally eight but had dropped to four because of timetabling issues. Pauline identified the individual attention she was able to give the students as advantageous, because 'their skills come on much, much quicker, much and much better... much more chilled out'. Double sessions were identified also as advantageous over single sessions in order to address the compression of activities by the timetable. There was only a limited possibility of obtaining these highly prized timetable slots.

Timetabling was also an important influence in the college. Malcolm contrasted the three hour sessions in college with the shorter sessions in schools. Working in a timely manner is important in professional cookery, and the sense of needing to work within the limits of the timetable was enhanced by the requirement to prepare food for the restaurant. The organisation of space was also significant. In contrast with the school's kitchen, which was set up like a number of domestic kitchens and students cooked on a domestic scale, in the college, the kitchens were similar to those to be experienced in the workplace. The suite of rooms with two kitchens and a classroom with good equipment supported the curriculum well and Malcolm used a wide range of media. The fact the students were given professional clothes, knives and a cookery book suggests good resourcing of this area. The college students also received a bursary, whereas the school students had to pay for their ingredients and provide 
containers and dishes. Staff-student ratios were good at roughly 9-1 (the limit is 14), but this was partly governed by Health and Safety legislation.

\section{Life Sciences}

\section{Individual factors}

The unit in the school was taught by two teachers during the course of the observations. The first teacher Donald, the permanent biology teacher, who had a motorbike accident in October was replaced by Debbie a supply teacher, who took the class up to Christmas.

Donald thought teaching was amongst the three worst jobs that anyone could do. $\mathrm{He}$ did his degree in human biology then a post graduate course in Bio-technology. He was attracted to teaching because of the career structure and the security: 'you've got a qualification in something you become a teacher. So that's always quite handy cause it's you know what you gonna do'. He quite liked the demonstrating he did as a postgraduate student, which is what gave him the idea of going into teaching.

He described his approach to teaching as relaxed, although he remarked that he likes to set out the boundaries in terms of discipline early on so that the students know exactly what he expects of them. He explained how the change in senior management and the general disciplinary procedures have helped to create a better environment in the school for teaching and learning. For Donald, teaching was a performance.

Donald: 'it's an act, it's a show. ....I think that if it's enjoyable that you learn more'.

Interviewer: 'So how do you do that...'? 
Donald: 'I don't know, I ..dance...oh I don’t know, do silly voices, sing...' In terms of the course content, 'it comes in sheets. You know, every topic is in work sheets' (Donald). His performances were designed to make the whole experience more enjoyable and help the students remember the content. He took the SQA arrangements documents and used them to write booklets with all the relevant information and little exercises for students to do. He also used the past exam papers as he thought that it is difficult to know everything they may be tested on from the arrangement documents. He was trying to make the new course as short and concise as possible. This was partly in response to students' perceived lack of motivation. This seemed to result in what he called a 'lead from the front approach'. This was significant in terms of his approach to teaching. He stated that the students at this level don't actually like doing practicals - although the students were not of the same opinion on this issue. He was very careful that they learnt the specific terms for the content they were covering. As he went through the PowerPoint presentations, the students filled in the correct answers in their booklets.

The supply teacher, Debbie, had a very different background.

'I used to be a Agricultural Biologist.... and I had my kids and then I did some voluntary work in schools and then some err special educational needs stuff in playgroups and primary, and then up here (to secondary) as an Auxiliary and then changed (trained to be a teacher)'.

While she worked in the industry she did research and development both in the laboratory and out in the field. She had a very different educational and training route into teaching. When she left school she got a job and then studied towards some vocational qualifications before gaining a degree in life sciences. By contrast with 
Donald, she considered Biology to be a practice-based subject but accepted that there were other ways of viewing it. This contrasting view of the nature of the subject, linked to her background, was significant in terms of her approach to teaching. Her route into teaching through vocational education and via an occupational career, which included both practice and research, was also significant in that she emphasised the various routes that students could take without dismissing those who were not looking to go to university as 'lacking motivation'.

The first class observed with Debbie was a practical lesson carried out in groups. Each group had an instruction sheet. She started by getting them thinking about what they were going to do and how. She had a maths problem on the board which also related to the theme of the practical. As the experiment progressed she constantly asked them questions, reminding them to think about why they were doing what they were doing. She did not give the answers but left them thinking about it and trying to work it out in their groups. Debbie explained that she got the idea for this class from the internet and chose it specifically because it was an experiment that they could do at home, as it did not need any specialist equipment. This illustrates how she connected other spaces with the classroom in a way that extended the prescribed curriculum beyond the immediate physical location of the classroom and its artefacts of teaching, learning and biology.

At the end of the lesson there was an informal chat as they waited for the bell to go. The students learnt that she had a son at university and that he commuted from home. She told them that there are various routes to university and they did not have to go straight there. One girl from the focus group said that her brother was in Iraq getting 
shot at and that she was going to join the army too, as all her family are in the forces. Debbie's response was simply to remark that she could do other things if she wanted.

In the college, the unit is taught by Isabelle who was a full time member of staff teaching both biology and chemistry in the science department. Isabelle had been working at Riverside College for 15 years:

'I love teaching. I love being in front of classes. I love teaching adults. I love seeing people come in with very little confidence, people that hated science at school, and all of a sudden they go, 'This is not so bad. This is ok! I can do this, I can achieve it!' I love seeing people go off to university and then, sometimes meeting them years later and they go, 'You know, I'd never had done that if I hadn't come to the college.'

She had started part time and gradually gained more hours, only recently going full time.

Isabelle did her degree specialising in biochemistry. She then went on to work in hospital laboratories for several years before starting a family. She stopped working for a while after her second child. When she was ready to go back to work, she did not want to go back in too the laboratories which 'had become very automated and boring'. She therefore applied for a part time lecturing post at Riverside College.

She was friendly but brisk and appeared to be very efficient in all she did. Isabelle's approach to teaching was very eclectic as she liked to use lots of different sorts of activities. Most of them were content centred. She liked to try lots of different ways to help them learn the content through stories, anecdotes, mind maps, role play and 
practical activities in the laboratory. It seemed that all the members of staff in the department worked closely together in the sense that they share teaching materials and ideas for learning activities.

Isabelle described her approach to teaching as very relaxed. She said that she encourages the students to stop her and ask questions if they are unclear about something. She thinks up activities to help the students when she gauges that they have not quite understood. She contrasted her own teaching to her experience of being a school student: 'the teacher just talked at you and you had to get on with it, whereas now teachers have to be much more aware of how people learn and try and use different strategies'. These included giving the students plenty of practice of doing the assessments and past papers. Isabelle combined a content driven approach with lots of different kinds of practical activities aimed at helping the students to learn the content, while also facilitating a 'learning to do' science. All three teachers in this subject therefore have slightly different approaches to the subject and to teaching, which seems to relate to their previous experience of studying and/or working with in the subject/occupational area.

The college students were mainly there for a specific career purpose - they wanted to become nurses, care workers or social workers and were doing this course as part of a wider programme of training. The few that were not sure what they wanted to do were the younger ones that had come straight from school. The school students were very mixed in terms of their motivations and expectations of doing the course. The one boy wanted to go on to do a sport related job and saw the course as being very relevant. He hoped to be going to college the following year. One girl was competing 
nationally in dance competitions and saw the relevance in terms of her own career in this direction. The other girls were less sure what they wanted to do; one wanted to do something to do with child care and another wanted to join the army. There were also a number of students who were rather lost and unsure in terms of the direction they would be going in.

The college and school students in this curriculum area were similar in the sense of there being a mix of students who were highly motivated and those who were rather unsure what they wanted to go on to do, and hence unsure how relevant biology might be to their future routes of progression. The approaches and strategies that the teachers implemented in the face of this diverse group were distinct and related firstly, to their view of the subject in terms of its practical or knowledge based nature; secondly, to their assumptions about the student body; and thirdly, to their ideas on how students learn.

\section{Organisational factors}

Behaviour and discipline were central concerns in the school. Both the teachers from the school talked quite a lot about the new Headteacher and how discipline was improving. There was a feeling that control had been taken back and senior management was very hands on in this respect. Both teachers also talked about particular strategies that had been implemented in relation to improving discipline on a school wide basis, but also strategies for maintaining order and discipline within the classroom to facilitate the teaching and learning environment. The more formally implemented quality assurance mechanisms from senior management reportedly helped uphold standards of discipline in the classroom and encouraged the 
implementation of policy initiatives. However, the less formal visibility of senior management around the school and entering classrooms was also noted for its effects on discipline and hence processes of curriculum making.

In the college the teacher talked about the importance of differentiating the learning experience from that of the school as many of the students had had very negative experiences at school. Isabelle also identified the size of class as being crucial. The priority of this teacher was finding ways to motivate the students so that they would stay on. Retention was therefore a major organisational issue. By contrast, in the school attainment was a far more important factor. Students were encouraged to do five Highers and those who did not want to take this route were dissuaded from returning to the school for further study.

The teaching and learning spaces in the college and the school were once again very different. The school building was new and very modern and considered to be well equipped in comparison to other schools in the area. The science department in the college had also been recently refurbished and was considered to be modern and well equipped. However, the way the spaces were distributed and used was very different. In the school each teacher had their own classroom, which was equipped to perform as both a traditional classroom and a laboratory. There were several biology classrooms, but each one belonged to a particular teacher. This meant there was no specialisation in terms of how the space was used. By contrast, the college had three main teaching spaces which were shared by the students and the teachers. There was one room which was set up as a traditional classroom, another as a large modern laboratory and a very large classroom fitted out with IT equipment and tables in 
groups to allow for a range of different layouts and types of group formations. The laboratory facility was modelled on an industrial laboratory and was quite distinct from the layout in the school. The distribution of space and who controlled it also impacted on the possibilities and types of professional dialogue that were enacted. In the college the lecturers all shared a small staff base where they kept all their teaching materials, swapped teaching ideas, chatted and drank coffee. In the school there was also a staff base but this was used in a different way given that each teacher also had their own classroom where they tended do more of their teaching preparation in isolation.

The college and school had a technician but the role of the technician in the college was very different from that in the school. In the school they were invisible during classes and only did very general technical tasks. In the college the technician prepared all the laboratories in advance of the teachers taking their groups into the space. She also helped the students with their experiments and contributed her industrial experience and practices to laboratory work. This was an important resource that impacted considerably on how the curriculum is enacted, enabling a much more practice based approach in the college. In the school, the teacher had to do all the preparation and supervision of any practical activities that occurred within the classroom.

\section{Technical Studies}

\section{Individual Factors}

The Higher Technology course in the school was taught by Gerald, who had a background in industry. After leaving school he did City and Guilds qualifications in 
motor mechanics before working for 12 years in a naval yard. Following this he completed a degree in engineering as a mature student and undertook a succession of local electronics/engineering related jobs. Following redundancy, he worked in England as a project manager, but this was short lived and he subsequently became redundant again. This uncertain set of experiences led him to return to Scotland, initially in youth work, then training as a teacher. At this point, he developed an interest in pedagogy, which has been subsequently developed in school. Gerald has worked at Woodland Academy since qualifying as a teacher, and while he has extensive life and career experience, he is comparatively new as a teacher, something he credits for his enthusiasm for his job. Part of this enthusiasm was evident in his extra-curricular activity running a football team. Gerald appeared to be a popular teacher who enjoyed good relationships with his classes.

Gerald espoused quite firm views about his teaching and students' learning, which appeared to be in some tension with the ways in which he was observed to teach. Decisions about practice are inevitably influenced by the practicalities of having to work within pre-defined assessment and school quality assurance frameworks, which may in part explain these tensions. Gerald's aspirations about his teaching had their roots in his industrial experience (a focus on experiential and relevant activities) and his experiences as a youth worker (an emphasis on the relational aspects of classroom practice) and this manifested itself in his desire to make lessons fun.

He saw students as individuals and was critical of one-size-fits-all approaches. He emphasised the role of dialogue in learning and stated the desire to do more practical work. However, there was a sense that the majority of the classroom experience of the students was driven primarily by the demands of getting through the knowledge- 
focused syllabus, even where this was plainly not what the teacher saw as an educational experience. In Gerald's case, the enacted curriculum seemed to be influenced more obviously by the organisational culture of the school.

Gerald had strong opinions about the place of his subject within the school curriculum. He was sensitive about colleagues viewing technology as purely a practical subject, seeing it instead as a high status academic subject. He talked about the 'ignorance' of other teachers, including those in guidance, about the breadth of the subject, and was critical of those who see design and technology as simply 'woodwork'. He discussed recent changes to provision, whereby foundation Standard Grade has been replaced by a less academic craft course, with a focus on practical skills, and of the increased orientation of the Standard Grade craft and design course toward the design aspect.

The situation at the college in terms of the teacher's background was both similar and different to that in the school. Higher Mechatronics was taught by Duncan, who also had a background in industry, having worked in the offshore oil industry for 7 years, where he was involved in electronics and computerised systems. In 1995 he left this industry following an injury. At this stage he retrained as a teacher, doing a 4 year BEd. Prior to working at Riverside College, Duncan worked at other colleges. Duncan was well known in local schools for his demonstrations of robotics (Robot Wars), where he promoted technology. The technology department at Riverside was split between 2 sites, with the bulk of the engineering being done at another campus.

Duncan was an enthusiast for technology and shared many interests with his students such as the web-based computer games he played in his spare time and a passion for taking apart and putting back together various electronic components and gadgets. $\mathrm{He}$ 
came across as being quite spontaneous in his approach to his teaching and appeared to be highly regarded by students. His espoused approach to teaching involved talking through procedures and letting the students loose on the internet to engage in personal and group-based inquiry. He claimed to be an advocate of group work and team building activities, although there was more evidence in the observations of individualised approaches to inquiry. He relied quite heavily on presentation technology and he used the SQA notes to structure his teaching, highlighting key passages and then talking through the content. He described these notes as didactic, suggesting that the content is quite prescriptive. He did not like the major influence of exams on the students' learning and on his teaching; he pointed to the decontextualised nature of the syllabus content, and sought through his teaching to bring in relevance to real life and variety to keep students interested, even where this means drift from the confines of the syllabus. In this respect he often drew upon his industrial experience. In one interview he referred to 'sneak[ing] education in there as well' to supplement the teaching to the test, and stated that he saw his role as broadening horizons as well as training students to pass the exam. Duncan suggested that the course was overcrowded in terms of content and assessments, stating that time constraints made practical work difficult. His approach to class management was fairly formal at first, but this soon relaxed as the course progressed.

The industrial background of this teacher seems to be a rich contributor to the curriculum-making process. His views about relevance and his contextualising of the curriculum in relation to the occupation were clear in the observed lessons and his descriptions of his teaching. This lead him to bring in additional content to make the SQA syllabus content more contextually relevant. In doing so, he draws upon a rich vein of occupational contextual knowledge. His background in the industry has a clear 
bearing on his pedagogical approaches. Duncan was always keen to promote student inquiry, even though he sometimes left insufficient time to do this. His background perhaps explains his approach to the assessments, which were built into the work programme rather than being seen as formalised tests. He used a good deal of formative assessment, allowing students to resubmit assessed work quickly.

As with the other case studies, there were some interesting differences between the student cohorts in the school and the college. The school students take the Higher in Technology for various reasons. Two boys aimed to progress from this to a university engineering course. A girl said that she just liked the subject. The students liked the teacher, whom they described as 'vibrant' and 'fun', albeit strict. They stated that they found much of the work difficult and tiring, as it involved a lot of listening, taking notes and answering questions. They believed that there were only limited chances to do practical work, although when opportunities for group or practical work occurred, they clearly enjoyed this. One student stated that the practical lesson was the best way to learn, as she was 'figuring out how it works' herself. The students saw passing Higher as the primary goal, in tandem with the teacher, and did not see any problem with being placed under pressure about grades.

The college class contained a mix of students, some full time at the college and the majority attending on afternoon release from local schools. These latter students described college as being more fun than school, even though they covered the same sort of work, and were tested similarly through regular national assessments. Students pointed to a more relaxed atmosphere in college. They stated that resources were better in college. An interesting perception was that more time was available for studying Highers at College, despite the roughly equivalent allocations of time at the 
two institutions. Uniformly, the students described school as dull, and complained about what they saw as petty restrictions on their behaviour - for example, restrictive access to the internet. They also noted that the college allowed students to do Highers who were prevented from doing so at school.

The nature of the student body had two obvious effects: the semi-formal approaches in the early weeks; and a tendency to finish the class early (the teacher cited the fact that school students are not used to long sessions). The positive attitude of the students towards the teacher and subject seemed to encourage a climate of trust, with students being allowed out of class for breaks during the long sessions. It also seemed to encourage the teacher to put in extra time out of class for tutorial work.

\section{Organisational Factors}

The department at Woodland Academy was large. There was some evidence of hierarchical decision-making processes, with policy set by the Principal Teacher (PT) in line with management generated priorities, reinforced by performance management procedures, including observed teaching by line managers. Despite this, there was clear evidence of a collegial and supportive environment and a shared departmental philosophy about learning and teaching, with considerable leeway for variations in individual practice. Gerald reported that there was generally a lack of time for (and a lack of an existing culture of) peer observation; this perhaps militated against the development of common thinking about teaching and shared practices. Departmental collaboration led to the production of schemes of work and the generation of strategies for teaching (e.g. peer assessment), approved by the PT. It also extended to staff with particular expertise in an area of the curriculum supporting colleagues who were less confident. 
Department meetings had a major focus on attainment and the dissemination of management and other policy. The department had been involved in a formative assessment pilot study, which attracted some funding. This had led to the generation of strategies for peer assessment, including peer marking and the use of traffic lighting. The impetus for this project was an Education Authority initiative, but the development was also in tune with the values of the staff in the department, having a focus on classroom dialogue and group work to promote learning. The school's involvement in these initiatives appears to be predominantly driven by pressure to raise attainment and improve the school's position on a league table of comparator schools. This focus was identified by Gerald as being the over-riding priority of the senior management.

Such pressures invariably encourage a style of teaching geared to meeting the demands of the arrangements documents and subject matter tested at the end of the year. Gerald made an effort to contextualise the maths elements, rather than teaching them separately, as did some of his colleagues, but ultimately his teaching was set up to prepare students for answering exam questions, including the teaching of strategies. While he did not like this approach, which he contrasted with education, he saw little other option. As he stated, the exam content was fairly predictable from year to year; and he was 'pretty good at predicting a test and teaching to it'. Moreover, despite his support for more interactive modes of teaching, the pressure was on him to do just this. Gerald was quite open about an apparent disjuncture between described and enacted practice, pointing to a number of factors that impacted on his teaching: lack of time, the fragmented nature of timetabling (which meant short periods), lack of equipment (such as that available in the college), the lack of a technician (which placed pressure on the teacher's already limited time) and the attainment agenda. 
The college data suggested a quite different focus and ethos in terms of the organisational factors that impact upon curriculum making. The attainment agenda appeared to be far less intrusive at the college than it was at the school, and a higher priority seemed to be given to retaining students throughout the year. In general, the impact of quality improvement procedures seemed to be less in the college than in school. Duncan talked about peer observation of teaching, which had increased in regularity since he came to the college. He stated that the focus was often on whether new resources were being used. Managers checked that meetings took place, but did not regularly attend them. Duncan stated that there was little management pressure in respect of results, but this was possibly because his results were good. The data imply a sense of laissez-faire and isolation, but this was possibly only the case in respect of this teacher/department. For example, he stated that he was the only person in his area teaching Highers, and the split site contributed to the isolation for the teachers in this part of the department. The relative isolation of the college lecturer in terms of being away from the main departmental site would seem to impact on the curriculum in that there was less opportunity for him to interact with colleagues and work collaboratively. This contrasted with the rather more collaborative nature of the school department, which in this case, was spatially and collaboratively closer together.

Resources are a key factor in the curriculum making process at college. IT resources are seen as being an enabling factor by students used to school procedures, but are also an inhibitor. While the college has better IT resources than the school, the unreliability of computers means that planned activities are not always possible, perhaps adding to the ad hoc nature of some of the observed teaching. 


\section{Inferences}

We have provided quite detailed description of the particular units researched and it is clear that the range of factors that impact upon the translation of the prescribed to enacted curriculum is multiple and complex. At one level, it is possible for us to draw out a range of individual and organisational factors through thematic analysis. For instance, the prior experiences of teachers and students, the spaces within which teaching and learning takes place and the artefacts around which they are structured, the different forms of discipline, timetabling, and the balance of the retention and attainment agendas all seem significant. Their effects can also be drawn out; teaching to assessment, the balance of practical and knowledge driven learning, the ways in which the curriculum is contextualised. However, to draw out such themes might imply that in some ways they can be controlled in order to produce greater standardisation. Our argument is somewhat different.

Although ostensibly taking similar units within a unified and rational curriculum framework, it is clear that the enacted curriculum varies significantly across the different sites of subject departments, and between school and college. A focus on individual and organisational factors helps us to understand how the translation from prescribed to enacted curriculum occurs. We may infer from this that schools and colleges may provide similar opportunities at a formal level, but they are very different organisations serving different student groups and with often different types of staff with varying professional formations. Curriculum-making is therefore very different in the different organisations. Of course neither schools, nor colleges, are 
homogenous groups and there will be differences in curriculum-making in institutions within each group. What implications can we infer from this?

If we take a rational view of curriculum, we might decry the differences in the enacted curriculum and seek ways to produce greater consistency. Further standardisation becomes necessary., and indeed it might be argued that this is a purpose of the specification inherent in credit and qualifications frameworks, as it assumes difference can and should be eradicated. However, such a view is problematic for a number of reasons. First, it conflates the outcomes of learning with the means of achieving them, raising issues of purpose, as noted elsewhere by the likes of Young (2007 and Allais (2007) and cited earlier. Second, and there is some evidence from our research to support this, an over-emphasis on outcomes has been shown to narrow the enacted curriculum, as teachers seek to teach to the test despite Raffe's (2007) suggestion that the looseness of Scotland's framework has militated against such rigidity. This effect has been noted elsewhere (e.g. Torrance 1997, Lauder et al. 2007), and is consonant with Campbell's Law which noted many years ago, in the context of US assessment systems, the tendency for quantitative measures of social phenomena to distort the processes they are supposed to be measuring (Macdonald 2000). Third, the belief that such standardisation is indeed possible is a chimera, no matter how specified the frameworks. It is well established in the literature that teachers mediate policy to suit local circumstances and existing practices (Osborn et al. 1997) and that adaptation is the norm rather than the exception (Supovitz and Weinbaum 2008). Thus credit and qualifications frameworks cannot prevent such adaptation, but perhaps represent more a distorting factor, merely one amongst a 
myriad of others, including local conditions, that in their totality serve to explain how curriculum-making occurs and why it occurs in particular forms.

Thus an emphasis on outcomes as the determinant of curriculum making practices is misleading and potentially damaging, and we would argue that a practice focused view of curriculum is necessary. If we take such a view, it then becomes important to realise the ways in which the enacted curriculum is differentiated in order to avoid false assumptions about achievement, articulation and progression. It also becomes necessary to recognise that achieving similar outcomes as specified in the prescribed curriculum does not mean that one has engaged in equivalent learning, despite what might be inferred from the development of credit frameworks. Acquiring similar prescribed outcomes can be based upon participation in very different learning experiences. In this sense, some of the discussion about turning teachers into technicians through prescribed outcomes-based curriculum seems somewhat misplaced, as organisational and individual factors already do and inevitably will support the play of difference in curriculum-making. More creativity may be desired in curriculum-making, but this would entail addressing the existing play of difference, which is not simply about curriculum policy.

The existing play of difference is an effect of a whole range of factors that impact on curriculum making practices. A detailed description of these factors and their effects can start to unravel the complexity of the curriculum making process and help to avoid the simplifications that can be employed by policy makers and others in their attempts to promote standardised learning outcomes. 
These are significant inferences. The question then becomes one of the extent to which similar issues arise from the study of other curriculum areas, and how differentiated the enacted curriculum is across the full range of education and training providers. However rational the prescribed curriculum and credit structures may be, difference remains infused in the enacted curriculum. Equivalence of learning is therefore a far more substantive issue than the prescribed rational curriculum suggests.

Note

This article is based on a research project, Curriculum-Making in School and College, funded by the ESRC (RES -000-22-2452). Our thanks go to the staff and students that made this project possible.

\section{References}

Allais, S. 2007. Why the South African NQF Failed: lessons for countries wanting to introduce national qualifications frameworks. European Journal of Education, Vol. 42, No. 4, 521-547.

Bates, I. 1989. Versions of vocationalism: an analysis of some social and political influences on curriculum policy and practice. British Journal of Sociology of Education 10, no.2: 215-231.

Bloomer, M. 1997. Curriculum making in post-16 education. London: Routledge. 
Bryce, T. and W. Humes. 1999. Scottish secondary education: philosophy and practice. In Scottish education, eds. T.G.K. Bryce and W.M. Humes, Edinburgh: Edinburgh University Press.

Canning, R. 2007. A history of core skills development policy in Scotland. Scottish Educational Review 39, no.2: 138-147.

Cohen, D.K. 1988. Teaching practice: plus ca change...'. In Contributing to educational change: perspectives on policy and practice, ed. P.W. Jackson, Berkeley: McCutchan.

Cuban, L. 1984. How teachers taught: constancy and change in American classrooms 1890-1980. New York: Teachers College Press.

Cuban, L. 1988. Constancy and change in schools (1880s to the present). In Contributing to educational change: perspectives on policy and practice, ed. P.W. Jackson, Berkeley: McCutchan.

Cuban, L. 1998. How schools change reforms: redefining reform success and failure. Teachers College Record 99, no.3: 453-477.

Daniels, H. 2001. Vygotsky and pedagogy. London: Routledge.

Doyle, W. and G.A. Ponder. 1977, The practicality ethic in teacher decision-making. Interchange 8, no.1: 1-12.

Eisner, E.W. 1992. Educational reform and the ecology of schooling. Teachers College Record 93, no.4: 610-626. 
Elmore, R.F. 2004. School Reform for the Inside Out: policy, practice and performance, Cambridge, Mass.: Harvard Education Press.

Goodson, I.F. 2003. Professional knowledge, professional lives. Maidenhead: Open University Press.

Goodson, I.F. 2004. Understanding curriculum change: some warnings about restructuring initiatives. In Social geographies of educational change, eds. F. Hérnandez and I.F. Goodson, London: Kluwer Academic Publishers.

Helsby, G. 1999. Changing teachers' work. Buckingham: Open University Press.

Higham, J.J.S. 2003. Curriculum change: a study of the implementation of general national vocational qualifications. The Curriculum Journal 14, no.3: 317-340.

James, D. and G. Biesta. 2007. Improving learning cultures in further education. London: Routledge.

Lang, M., J. Olson, H. Hansen and W Bunder. 1999. Professional development and the challenge of curriculum reform. In Changing schools/changing practices: perspectives on educational reform and teacher professionalism, eds. M. Lang, J. Olson, H. Hansen and W. Bunder, Louvain: Garant.

Lauder, H., P. Brown, H. Lauder, P. Brown, J-A. Dillabough and A. H. Halsey. 2007. Introduction: The Prospects for Education: Individualization, Globalization, and Social Change 1. In Education, Globalization and Social Change, eds. H. Lauder, P. Brown, J-A. Dillabough and A. H. Halsey, Oxford: Oxford University Press. 
Leech, M. 1999. Further education in Scotland post-incorporation. In Scottish Education, eds. T.G.K. Bryce and W.M. Humes, Edinburgh: Edinburgh University Press.

Levin B. 1998. An epidemic of education policy: (what) can we learn from each other? Comparative Education 34, no.2: 131-141.

Macdonald, B. 2000. How education became nobody's business. In Images of Educational Change, eds. H. Altrichter and J. Elliott, Buckingham: Open University Press.

Mueller, J.A. and K.H. Hovde. 2008. Theme and Variation in the Enactment of Reform: case studies. In The Implementation gap: understanding reform in high schools, eds. J.A. Supovitz and E.H. Weinbaum, New York: Teachers College Press.

Osborn, M., P. Croll, P. Broadfoot, A. Pollard, E. McNess and P. Triggs. 1997. Policy into practice and practice into policy: creative mediation in the primary classroom. In Teachers and the national curriculum, eds. G. Helsby and G. McCulloch, G. London: Cassell.

Raffe, D. 2007. Making Haste Slowly: the evolution of a unified qualifications framework in Scotland. European Journal of Education, Vol. 42, No. 4, 485502.

Sarason, S.B. 1990. The Predictable Failure of Educational Reform. Oxford: JosseyBass Publishers. 
Smyth, J., P. McInerney, R. Hattam and M. Lawson. 1998. Teacher learning: the way out of the school restructuring miasma. International Journal of Leadership in Education : 95-109.

Spillane, J. 1999. External reform efforts and teachers' initiatives to reconstruct their practice: the mediating role of teachers' zones of enactment. Journal of Curriculum Studies 31, no.2: 143-175.

Supovitz, J.A. and E.H. Weinbaum. 2008. Reform Implementation Revisited. In The Implementation gap: understanding reform in high schools, eds. J.A. Supovitz and E.H. Weinbaum, New York: Teachers College Press.

Thomson, C. 2003. Further education in Scotland. In Scottish Education, $2^{\text {nd }}$ edition, eds. T.G.K. Bryce and W.M. Humes, Edinburgh: Edinburgh University Press.

Torrance, H. (1997). Assessment, accountability, and standards: using assessment to control the reform of schooling. In Education: culture, economy, society, eds. A. H. Halsey, H. Lauder, P. Brown \& A. S. Wells, Oxford: Oxford University Press.

Tyack, D. and L. Cuban. 1995. Tinkering toward utopia: a century of public school reform. Cambridge: Harvard University Press.

Young, M. 2007. Qualifications Frameworks: some conceptual issues. European Journal of Education, Vol. 42, No. 4, 445-457. 